\title{
A família Palmae na Reserva Biológica da Represa do Grama- Descoberto, Minas Gerais, Brasil
}

\author{
Marco Otávio Pivari ${ }^{1}$ \& Rafaela Campostrini Forzza ${ }^{2}$
}

\section{RESUMO}

(A família Palmae na Reserva Biológica da Represa do Grama - Descoberto, Minas Gerais, Brasil) O presente trabalho trata do levantamento das espécies de Palmae ocorrentes na Reserva Biológica da Represa do Grama, localizada na Zona da Mata do estado de Minas Gerais, no município de Descoberto. A Reserva abrange uma área de 263,8 hectares, de floresta estacional semidecidual. Foram encontradas para a família sete espécies distribuídas em seis gêneros: Astrocaryum aculeatissimum, Attalea oleifera, Bactris vulgaris, Euterpe edulis, Geonoma brevispatha, G. rubescens e Syagrus romanzoffiana. São fornecidas chave de identificação, descrições, ilustrações, dados sobre distribuição geográfica e comentários para cada espécie.

Palavras-chave: Palmae, Arecaceae, Taxonomia, Zona da Mata de Minas Gerais.

\section{Abstract}

(The family Palmae in the Reserva Biológica da Represa do Grama - Descoberto, Minas Gerais, Brazil) A survey consisting of the taxonomic study of the Palmae species in the Reserva Biológica da Represa do Grama, located at the Zona da Mata of Minas Gerais State, in the municipal district of Descoberto. The area covers 263.8 hectares of stationary semidecidual forest. Six genera and seven species were found:Astrocaryum aculeatissimum, Attalea oleifera, Bactris vulgaris, Euterpe edulis, Geonoma brevispatha, G. rubescens and Syagrus romanzoffiana. Identification keys, descriptions, ilustrations, range, habit and comments for each species are furnished.

Key-words: Palmae, Arecaceae, Taxonomy, Zona da Mata of Minas Gerais.

\section{INTRODUÇÃO}

Encravado na porção sudeste do Brasil, Minas Gerais ocupa cerca de 7\% do território federal e apresenta em seus domínios três grandes fitofisionomias: a porção centroocidental constituída por áreas de cerrado; a porção norte coberta por expansões da caatinga e a porção leste-sudeste constituída por prolongamentos da floresta atlântica (Martins 2000).

A região da Zona da Mata é constituída pelas florestas estacionais semideciduais montanas e submontanas, que se encontram extremamente fragmentadas devido a diversos tipos de perturbações como fogo, pecuária, retirada seletiva de madeira e a crescente expansão das áreas urbanas (Oliveira-Filho et al. 1994, Meira-Neto et al. 1997, Silva 2000). Assim, a grande área de domínio da floresta atlântica, cuja cobertura original correspondia a $40 \%$ do estado de Minas Gerais, atualmente está representada por cerca de 3\% (CETEC 1987).

Paradoxalmente, poucos estudos florísticos foram desenvolvidos nesta região. Este fato está refletido nas coleções científicas que representam muito pouco da diversidade das matas mineiras e nas poucas publicações que contemplam esta região. Dentro desse contexto, o presente estudo teve como objetivo o levantamento das espécies de Palmae ocorrentes na Reserva do Grama, a fim de incrementar o conhecimento sobre a vegetação da Zona da Mata de Minas Gerais e contribuir para o conhecimento taxonômico e biogeográfico da família.

\section{Material e Métodos}

A Reserva Biológica da Represa do Grama localiza-se na Serra do Relógio, Zona da Mata de Minas Gerais, no Município de Descoberto ( $\left.21^{\circ} 25^{\prime} \mathrm{S}-42^{\circ} 56^{\prime} \mathrm{W}\right)$, cerca de 100 
km ao nordeste de Juiz de Fora. A Reserva Biológica foi criada em 1971 porém, o processo teve início em 1911 com a aquisição das terras para manutenção da floresta e dos recursos hídricos. A Reserva abrange uma área de 263,8 hectares de floresta estacional semidecidual montana que abriga em seu interior a nascentes de vários córregos, dos quais ocorre a captação de água para abastecimento parcial dos municípios de Descoberto e de São João Nepomuceno (Menini Neto et al. 2004).

Para o desenvolvimento desse trabalho foram realizadas expedições periódicas à Reserva Biológica da Represa do Grama de agosto de 1999 a janeiro de 2004, onde as amostras de materiais férteis foram coletadas e incorporadas à coleção do herbário CESJ. As descrições e as ilustrações das espécies foram elaboradas com base nos materiais coletados na Reserva e a terminologia morfológica adotada foi baseada as definições contidas em Radford et al. (1974), Moore \& Uhl (1982) e Uhl \& Dransfield (1987).

\section{Resultados e Discussão}

A família Palmae apresenta distribuição pantropical, sendo especialmente diversificada na Ásia Tropical e América do Sul. Nas Américas, são encontrados 67 gêneros e aproximadamente 1.440 espécies, das quais cerca de 200 espécies e 39 gêneros são registrados para o Brasil. Para a floresta atlântica são referidos 10 gêneros e aproximadamente 40 espécies (Henderson et al. 1995). Na Reserva Biológica da Represa do Grama, foram encontrados sete espécies e seis gêneros: Astrocaryum aculeatissimum, Attalea oleifera, Bactris vulgaris, Euterpe edulis, Geonoma brevispatha, G. rubescens e Syagrus romanzoffiana.

Segundo Silva (2000), a floresta estacional semidecidual submontana e montana madura apresenta-se com três extratos: dois arbóreos e um herbáceo-arbustivo. O primeiro que forma um dossel contínuo tem seu limite em torno dos 25 metros de altura, o segundo extrato, com cerca de 15 metros, possui elementos jovens do primeiro extrato e espécies próprias. O terceiro extrato é composto por plântulas, espécies herbáceas e arvoretas que não ultrapassam 3 metros de altura.

$\mathrm{Na}$ Reserva Biológica da Represa do Grama as espécies de Palmae são encontradas nos três extratos acima descritos e são importantes componentes da fisionomia local. Attalea oleifera é a única espécie que faz parte do dossel e forma grandes adensamentos principalmente em áreas de encosta e próximo de áreas alteradas na borda da Reserva. No segundo extrato são encontradas Astrocaryum aculeatissimum e Syagrus romanzoffiana, ocorrendo principalmente nas áreas mais secas, e Euterpe edulis que forma grandes populações ao longo dos diversos cursos d'água que cortam a área. No extrato herbáceoarbustivo ocorrem Bactris vulgaris, da qual são encontrados indivíduos distribuídos de forma esparsa e em locais bem drenados, e Geonoma brevispatha e G. rubescens que ocorrem em locais de solo encharcado, em geral juntamente com Euterpe edulis.

\section{Chave para identificação das espécies de Palmae ocorrentes na Reserva Biológica da Represa do Grama}

1. Plantas com estipe e folhas armados.

2. Planta com 1,5-2,7 m alt.; folíolos verdes na face abaxial; bráctea peduncular $12-16 \mathrm{~cm}$ compr. 3. Bactris vulgaris

2'. Planta com 4,6-10 m alt.; folíolos cinéreos na face abaxial; bráctea peduncular ca. $60 \mathrm{~cm}$ compr. 1. Astrocaryum aculeatissimum

1'. Plantas com estipe e folhas inermes.

3. Bráctea peduncular 16-42 cm compr.; estipe com cicatrizes foliares dispostas regularmente. 
4. Planta solitária; inflorescência glabra, ramificações até segunda ordem 5. Geonoma brevispatha

4'. Planta cespitosa; inflorescência tomentosa, sem ramificações até segunda ordem

6. Geonoma rubescens

3'. Bráctea peduncular maior que $1 \mathrm{~m}$ compr.; estipe com cicatrizes foliares dispostas irregularmente.

5. Folíolos em diferentes planos, distribuídos irregularmente ao longo da raque

7. Syagrus romanzoffiana

5'. Folíolos em um único plano, distribuídos regularmente ao longo da raque.

6. Raquilas 17-23 cm compr.; frutos 5,6-6,3 cm compr.

2. Attalea oleifera

6'. Raquilas 71-88 cm compr.; frutos $1,2-1,5 \mathrm{~cm}$ compr.

4. Euterpe edulis

1. Astrocaryum aculeatissimum (Schott) Burret., Repert.Spec. Nov. Regni Veg. 35:152. 1934.

Plantas 4,6-10 m alt., cespitosas. Estipe ca. $5 \mathrm{~m}$ compr., até $28 \mathrm{~cm}$ diâm., ereto, enegrecido, cicatrizes foliares pouco evidentes, densamente armado, acúleos ca. $4 \mathrm{~cm}$ compr. Folhas 6-8; 2,5-5 m compr., algumas vezes marcescentes; bainha ca. $80 \mathrm{~cm}$, nigrescente, margem fibrosa, armada, acúleos 3-4 cm compr.; pecíolo ca. 160 x 1,3 cm, subcilíndrico, acúleos negros, com até $4,1 \mathrm{~cm}$ compr.; raque ca. 2,2 m compr., armada, acúleos com até 4,5 cm compr.; folíolos 48-53, discolores, cinéreos na face abaxial, distribuídos regularmente na raque, dispostos em um ou mais planos, medianos 42-48 x 0,9-1,1 cm, ápice acuminado, margem aculeada, acúleos ca. $2 \mathrm{~mm}$. Inflorescência pendente, interfoliar; profilo ca. 2,5 x 8 $\mathrm{cm}$, pardo, recoberto por tricomas alvos; bráctea peduncular ca. $60 \times 6 \mathrm{~cm}$, fibrosa, parda, armada, acúleos ca. $2,8 \mathrm{~cm}$ compr.; raque ca. $50 \mathrm{~cm}$ compr., ca. $8 \mathrm{~cm}$ diâm., armado, acúleos ca. $2 \mathrm{~mm}$ compr.; raquilas $30-39,5-14 \mathrm{~cm}$ compr., inermes. Flores estaminadas ca. 6 x 4 mm compr., amarelas; sépalas ca. $1 \times 1 \mathrm{~mm}$, hialinas; pétalas ca. 6 × 2-3 mm, acuminadas; estames 6 , epipétalos, filetes ca. $1,5 \mathrm{~mm}$ compr., anteras ca. $1 \mathrm{~mm}$ compr., dorsifixas. Flores pistiladas ca. 5 × $3 \mathrm{~mm}$ compr., amarelas; sépalas menores que $1 \mathrm{~mm}$, elípticas; pétalas ca. 5 x $2 \mathrm{~mm}$, acuminadas; pistilo ca. $2 \mathrm{~mm}$ compr. Frutos 5,5-6,5 cm compr., rostro 4-6 $\mathrm{mm}$; perianto persistente; epicarpo ca. $2 \mathrm{~mm}$ espessura, lenhoso, castanho, recoberto por acúleos de 1-3 mm compr. e escamas ferrugíneas; mesocarpo ca. $2 \mathrm{~mm}$. de espessura, fibroso, creme; endocarpo papiráceo, nigrescente. Semente 1; endosperma líquido, adocicado e transparente.

Nome popular local: brejaúba.

Material examinado: BRASIL, MINAS GERAIS: Descoberto: Reserva Biológica da Represa do Grama: V.2001, Fazza et al. 1, fl. e fr. (CESJ); III.2002., Forzza et al. 2093, fl. (CESJ, RB, SPF).

O gênero Astrocaryum reúne 18 espécies que se caracterizam por apresentar estipe, folhas e brácteas pedunculares densamente armados. Ocorre do México ao Brasil, com centro de diversidade na região amazônica. $\mathrm{Na}$ floresta atlântica o gênero é representado apenas por A. aculeatissimum, que pode ser encontrada desde a Bahia até o Paraná preferencialmente nas florestas úmidas em locais não inundáveis ou em áreas de pastagem (Henderson et al. 1995).

Astrocaryum aculeatissimum diferenciase das demais Palmae da Reserva por ser uma planta cespitosa de estipe densamente armado, além de possuir folíolos regularmente distribuídos em um ou mais planos e inflorescência interfoliar. $\mathrm{Na}$ área estudada, a espécie ocorre preferencialmente nas encostas mais íngremes e forma densas populações.

As folhas de A. aculeatissimum são empregadas na confecção de vassouras e chapéus, assim como na construção de casas e o caule é utilizado por algumas populações indígenas para confeccionar o arco-e-flecha (Noblick 1991). O endosperma líquido por sua vez é usado na medicina popular local. 
2. Attalea oleifera Barb. Rodr., Nov. Res. Bras. Rio de Janeiro 7: 123. 1881.

Figura 1: a-b

Plantas 10-13 m alt., solitárias. Estipe 6$10 \mathrm{~m}$ compr., ca. $1,10 \mathrm{~m}$ diâm., ereto, pardo, com cicatrizes foliares dispostas irregularmente, inerme. Folhas 12-16, ca. 5,9 m compr., algumas marcescentes; bainha 0,9-1,3 x 0,6$0,8 \mathrm{~m}$, fibrosa, pardacenta, inerme; pecíolo ca. $70 \times 8 \mathrm{~cm}$, quadrangular, lepidoto, cinéreo na face abaxial; raque ca. $4 \mathrm{~m}$ compr., inerme; folíolos 144-197, discolores, distribuídos regularmente em um único plano, medianos 89$98 \times 5-6 \mathrm{~cm}$, ápice acuminado a assimétrico, margem lisa. Inflorescência arqueadapendente, interfoliar; profilo não observado; bráctea peduncular ca. $160 \times 18 \mathrm{~cm}$, lenhosa, lepidota, cinérea, inerme; raque ca. $103 \mathrm{~cm}$ compr., ca. $11 \mathrm{~cm}$ diam., inerme; raquilas ca. $78,17-23 \mathrm{~cm}$ compr., inermes. Flores estaminadas 16-22 x 6-9 mm, creme; sépalas 1-3 x 1-2 mm, acuminadas; pétalas $15-20 \times 2$ $5 \mathrm{~mm}$, acuminadas; estames 9 , livres, filetes ca. $9 \mathrm{~mm}$ compr., anteras ca. $4 \mathrm{~mm}$ compr., dorsifixas. Flores pistiladas 3-4,3 x 1,8-2,1 cm, creme; sépalas 2,5-2,9 x 1,7-2,0 cm, triangulares; pétalas 3-4,1 x 1,5-1,8 cm, triangulares; anel de estaminódios ca. $1 \mathrm{~cm}$ compr.; pistilo não observado. Frutos 5,6-6,3 cm compr., 2,3-3,1 cm diâm., perianto persistente; epicarpo 2-3 $\mathrm{mm}$ de espessura, fibroso, recoberto por indumento castanho; mesocarpo 4-6 $\mathrm{mm}$ de espessura, fibroso, castanho; endocarpo 5-6 mm de espessura, lenhoso, castanho. Semente 1-2; endosperma carnoso, homogêneo, alvo.

Nome popular local: indaiá

Material examinado: BRASIL. MINAS GERAIS: Descoberto. Reserva Biológica da Represa do Grama: IX.2001, Fazza et al. 6, fl. e fr. (CESJ); III.2002, Forzza et al. 2092, fr. (CESJ, RB).

O gênero Attalea é composto por 29 espécies, das quais nove ocorrem nos domínios da floresta atlântica (Henderson et al. 1995). Attalea oleifera pode ser facilmente diferenciada das demais espécies da família ocorrentes na Reserva por apresentar grandes estipes solitários, sendo esta a maior e mais comum das espécies encontradas na paisagem da área de estudo. Nota-se os folíolos distribuídos regularmente em um único plano, folhas divergentes e decíduas, além de inflorescência pendente e interfoliar.

Attalea oleifera ocorre na costa atlântica do Brasil, nas Regiões Sudeste e Nordeste, normalmente em áreas florestais chegando ao cerrado até $800 \mathrm{~m}$ de altitude. Glassman (1977) cita $A$. oleifera para o estado de Goiás, apontando sua grande semelhança com $A$. burretiana Bondar. Segundo Anderson \& Balick (1988), A. oleifera pode ocorrer em áreas degradadas sendo que as suas populações crescem de tal forma, que chegam a constituir elemento dominante da paisagem. Este fato é observado em algumas encostas da Reserva onde a floresta se encontra mais alterada.

As folhas desta palmeira são geralmente utilizadas para construção de sapês. Já as castanhas, são consumidas cruas ou assadas e seu óleo é empregado no preparo de doces (Henderson et al. 1995, Pinheiro \& Balick 1987). A população local utiliza as folhas para cobertura de casas e confecção de vassouras, além de consumir o palmito e os frutos.

3. Bactris vulgaris Barb. Rodr., Enum. Palm. Nov. Prot. Append.: 42. 1879.

Figura 1: c-d

Plantas 1,5-2,7 $\mathrm{m}$ alt., cespitosas. Geralmente sem estipe ou algumas vezes com estipe até $1,4 \mathrm{~m}$ compr. e ca. $9 \mathrm{~cm}$ diâm., ereto a arqueado, pardacento, cicatrizes foliares pouco evidentes, armado; acúleos ca. 3,6 cm compr. Folhas 3-9; ca. 1,55 m compr., algumas marcescentes; bainha ca. $23 \times 9 \mathrm{~cm}$, fibrosa, ferrugínea, armada, acúleos negros, $0,5-2,9 \mathrm{~cm}$ compr.; pecíolo 45-64 x 0,6-1 cm, cilíndrico, armado, acúleos negros, 0,3-4,5 cm compr.; raque ca. 1,4 m compr., armada; folíolos 2530 , verdes em ambas as faces, distribuídos irregularmente e dispostos em diferentes planos; folíolos medianos $27-29 \times 2 \mathrm{~cm}$, ápice 


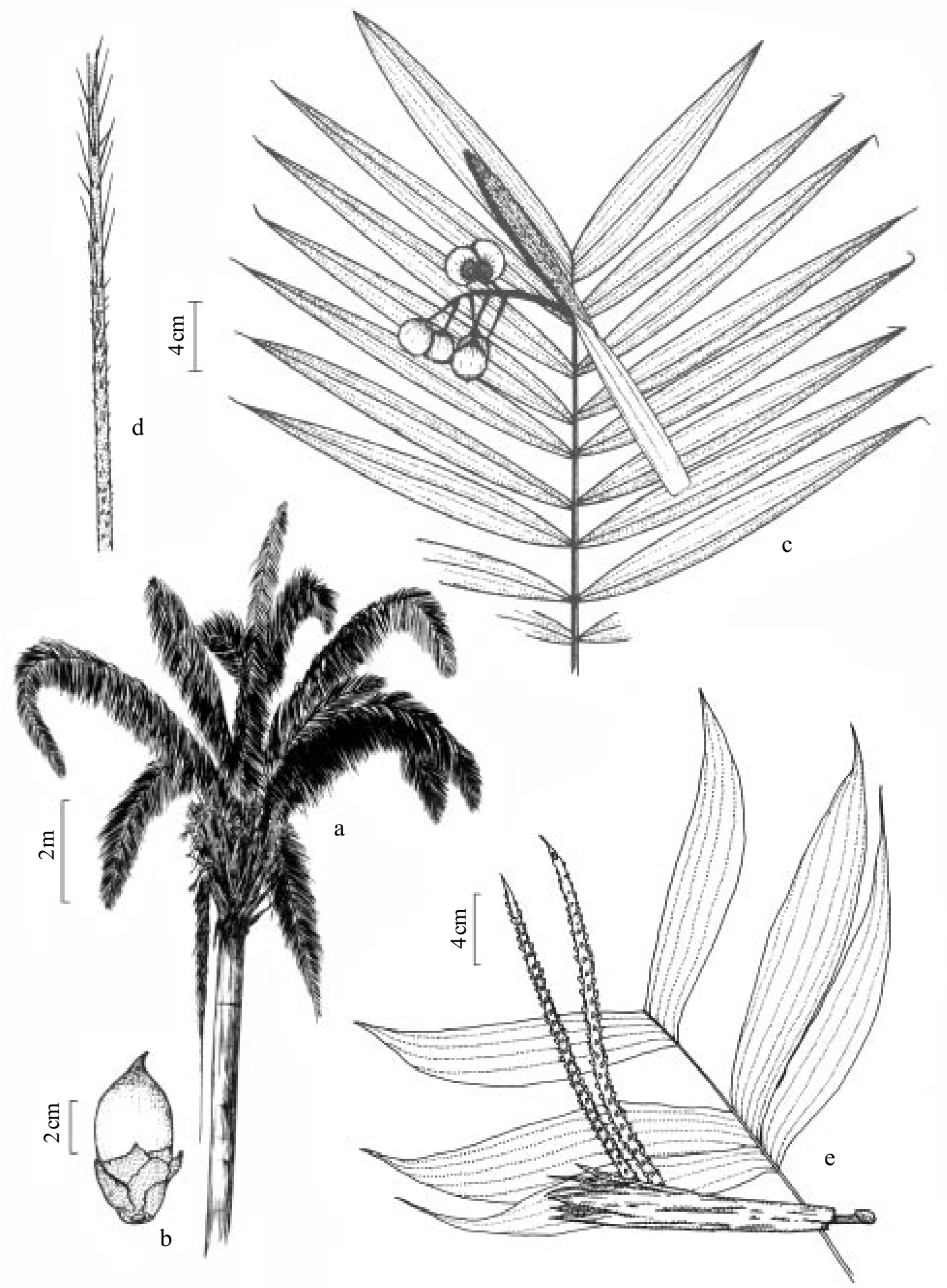

Figura 1 - Attalea oleifera Barb. Rodr.: a - hábito; b - fruto. Bactris vulgaris Barb. Rodr.: c - parte da folha, bráctea peduncular e frutos; d - parte do pecíolo. Geonoma rubescens Barb. Rodr.: e - folha, bráctea peduncular e inflorescência. 
acuminado, margem aculeada, acúleos 1-2 mm compr. Inflorescência pendente, interfoliar; profilo 10-12 x 1,2-1,8 cm, paleáceo, inerme; bráctea peduncular $12-16$ x 1,6-2,2 cm, fibrosa, parda, densamente aculeada, acúleos negros, ca.1,3 cm compr.; raque ca. $19 \mathrm{~cm}$ compr., 5$8 \mathrm{~mm}$ diâm., inerme; raquilas $6-8$, ca. $14 \mathrm{~cm}$ compr., inermes. Flores não observadas. Frutos 1,6-1,9 cm compr., ca. $6,5 \mathrm{~cm}$ diâm., perianto persistente; epicarpo $0,5 \mathrm{~mm}$ espessura, fibroso, castanho, glabro; mesocarpo ca. $1 \mathrm{~mm}$ de espessura, lenhoso, castanho; endocarpo ca. $1 \mathrm{~mm}$ de espessura, fibroso, pardo. Semente 1; endosperma carnoso, homogêneo alvo.

Nome popular local: brejaubinha.

Material examinado: BRASIL. MINAS GERAIS. Descoberto. Reserva Biológica da Represa do Grama: X.2001, Fazza et al. 35, fr. (CESJ); IV.2002, Pivari et al. 92, fr. (CESJ); IX.2002, Meireles et al. 1169, fr. (CESJ).

Bactris é constituído por 64 espécies com ampla distribuição nas Américas, ocorrendo do México ao Paraguai em áreas florestais, geralmente próximo a cursos d'água, savanas e áreas degradadas. Para floresta atlântica são registradas 13 espécies (Henderson et al. 1995).

Os indivíduos de $B$. vulgaris diferenciamse na área estudada pelo hábito cespitoso e acaulescente, embora algumas vezes possa apresentar caules de até $1,4 \mathrm{~m}$ de comprimento. As folhas são densamente armadas e os folíolos são irregularmente distribuídos em diferentes planos. B. vulgaris distribui-se pela costa Atlântica do Brasil, nos estados da Região Sudeste e Bahia, ocorrendo normalmente no interior de florestas úmidas em áreas não inundáveis, abaixo de $700 \mathrm{~m}$ de altitude (Henderson et al. 1995).

$\mathrm{Na}$ Reserva esta espécie é a menos freqüente dentre as palmeiras e não a relatos de sua utilização pela população local.

4. Euterpe edulis Mart., Hist. Nat. Palm. 2(2):33. t. 32. 1823.

Plantas 12-15 m alt., solitárias. Estipe ca. 12 m compr. e 43-47 cm diâm., ereto, castanhocinéreo, cicatrizes foliares dispostas irregularmente, inerme. Folhas 8-15; 1,3-2,4 m compr., algumas marcescentes; bainha ca. 1,5 $\mathrm{m} \times 19 \mathrm{~cm}$, fibrosa, pardacenta, inerme; pecíolo ca. $29 \times 3 \mathrm{~cm}$, triangular, canaliculado, inerme; raque ca. $1 \mathrm{~m}$ compr., face abaxial coberta por indumento ferrugíneo; folíolos 44-83, discolores, regularmente distribuídos e dispostos em um plano, medianos 73-94 x 2-3 $\mathrm{cm}$, ápice acuminado, margem lisa. Inflorescência pendente, infrafoliar; profilo não observado; bráctea peduncular ca. 105 x 10 cm, cartácea, ferrugínea, inerme; raque ca. 86 cm compr., 5 cm diâm., inerme; raquilas numerosas, 71-88 cm compr., inermes. Flores estaminadas 5-7 x 2-3 mm, creme; sépalas 2 x $1 \mathrm{~mm}$, acuminadas; pétalas 4-6 × $2 \mathrm{~mm}$, elípticas a lanceoladas; estames 6 , livres, filetes 2-3 mm compr., anteras 4-5 mm compr., dorsifixas. Flores pistiladas ca. 5 × $4 \mathrm{~mm}$, creme; sépalas ca. $3 \times 4 \mathrm{~mm}$, elípticas; pétalas 3 x 3-4 mm compr., elípticas; estaminódios 3, ca. $1 \mathrm{~mm}$ compr.; pistilo $2-3 \mathrm{~mm}$ compr. Frutos 1,2-1,5 cm compr., 1,1-1,4 cm diâm., perianto persistente; epicarpo ca. $1 \mathrm{~mm}$ de espessura, fibroso, castanho, glabro; mesocarpo ca. $1 \mathrm{~mm}$ de espessura, fibroso, esverdeado; endocarpo ca. $1 \mathrm{~mm}$ de espessura, fibroso, amarelo. Semente 1; endosperma carnoso, com reentrância mediana, alvo.

Nome popular local: palmito-juçara

Material examinado: BRASIL, MINAS GERAIS: Descoberto. Reserva Biológica da Represa do Grama: III.2001, Fazza et al. 4, fl. (CESJ); V.2001, Fazza et al. 3, fr. (CESJ).

O gênero Euterpe é composto por sete espécies que se distribuem da América Central à América do Sul, sendo E. edulis a única a ocorrer nos domínios da floresta atlântica brasileira, entre os estados do Rio Grande do Norte ao Rio Grande do Sul, além de Argentina e Paraguai (Henderson et al. 1995).

Euterpe edulis é de fácil reconhecimento devido ao longo estipe (12-15 m), solitário, inerme, além de apresentar inflorescência infrafoliar. Forma grandes populações em geral próximo de cursos d'água ou em áreas de pastagens nas proximidades da Reserva. 
O palmito obtido de E. edulis é largamente utilizado na culinária brasileira devido a seu apreciado paladar. O extrativismo exacerbado ao longo dos séculos, vem contribuindo para diminuição acentuada das populações desta espécie levando a inclusão da mesma na Lista das Espécies Ameaçadas de Extinção da Flora de Minas Gerais (Mendonça \& Lins 2000) e na Lista Oficial do IBAMA (MelloFilho et al. 1992). O extrativismo de palmito é uma das maiores ameaças à integridade da Reserva e vem contribuindo de forma acelerada para abertura de novas trilhas e clareiras.

5. Geonoma brevispatha Barb. Rodr., Enum. Palm. Nov. Prot. Append.: 41. 1879.

Plantas 2,5-5 m alt., solitárias. Estipe 1,5-3 $m$ compr. e 25-32 cm diâm., ereto a levemente arqueado, castanho-cinéreo, cicatrizes foliares evidentes, distribuídas regularmente, inerme. Folhas 14-19; 1-1,3 m compr.; bainha ca. 31 x 5 $\mathrm{cm}$, fibrosa, ferrugínea, inerme; pecíolo ca. $40 \mathrm{x}$ $0,8 \mathrm{~cm}$, triangular, canaliculado, inerme; raque ca. $66 \mathrm{~cm}$ compr., inerme; folíolos $22-24$, verdes em ambas faces, regularmente distribuídos e dispostos em um único plano, medianos 32-46 x 1,3-2,0 cm, ápice geralmente acuminado, margem lisa. Inflorescência arqueada, interfoliar; profilo não observado; bráctea peduncular 3142 × 3-4 cm, membranácea a fibrosa, parda, inerme; raque ca. $74 \mathrm{~cm}$ compr., 3,5-4 cm diâm., inerme; raquilas 8-23, 23-34 cm compr., inermes, com ramificações de segunda ordem. Flores estaminadas ca. $3 \times 2 \mathrm{~mm}$, creme; sépalas ca. 2 x $1 \mathrm{~mm}$, acuminadas; pétalas ca. $2 \times 1 \mathrm{~mm}$, acuminadas; estames 6 , monadelfos, filetes ca. $2 \mathrm{~mm}$ compr., anteras ca. $1,5 \mathrm{~mm}$ compr. Flores pistiladas $4 \times 2 \mathrm{~mm}$, creme; sépalas 2-3 x $2 \mathrm{~mm}$, carenadas; pétalas ca. 4 × $2 \mathrm{~mm}$; pistilo ca. 1 $\mathrm{mm}$ compr. Frutos ca. $1 \mathrm{~cm}$ compr., 7-8 mm diâm., perianto decíduo; epicarpo ca. $1 \mathrm{~mm}$ de espessura, lenhoso, nigrescente, glabro; mesocarpo ca. $1 \mathrm{~mm}$ de espessura, fibroso, castanho; endocarpo ca. $1 \mathrm{~mm}$ de espessura, fibroso, pardo. Semente 1; endosperma carnoso, homogêneo, alvo.

Nome popular local: sem relatos.
Material examinado: BRASIL, MINAS GERAIS: Descoberto. Reserva Biológica da Represa do Grama: V.2001, Fazza et al. 2, fl. e fr. (CESJ); IX.2001, Fazza et al. 5, fl. e fr. (CESJ); I.2001, Forzza et al. 1748, fl. e fr. (CESJ); IV.2002, Pivari et al. 91, fl.(CESJ).

Segundo Henderson (1995), o gênero Geonoma reúne 51 espécies distribuídas por toda a América Tropical. Para a floresta atlântica são registradas oito espécies, das quais duas ocorrem na Reserva: G. brevispatha e G. rubescens.

Geonoma brevispatha apresenta grandes populações na área ocorrendo preferencialmente próximos a cursos d'água. São solitárias e apresentam porte médio (até 5 $\mathrm{m}$ de altura), com folíolos regularmente distribuídos em um único plano e inflorescência interfoliar. A espécie apresenta ampla distribuição geográfica, ocorrendo na floresta atlântica, Planalto Central, Peru, Bolívia e Paraguai, em florestas úmidas, florestas de galeria ou áreas pantanosas entre 400 e 1.600 $\mathrm{m}$ de altitude, normalmente associada a cursos d'água (Henderson et al. 1995).

Geonoma brevispatha possui duas variedades: G. brevispatha var. brevispatha e G. brevispatha var. occidentalis, que se diferenciam pelos folíolos, posição da inflorescência e distribuição geográfica (Henderson et al. 1995). Segundo este mesmo autor, o complexo formado por $G$. brevispatha, G. pohliana, G. gamiova e G. schottiana necessita de estudos mais detalhados uma vez que estas espécies parecem apresentar um continuo nas variações morfológicas.

As folhas desta espécie são utilizadas para cobertura de abrigos e confecção de cestos, além do caule que pode ser empregado como cabo para ferramentas (Wessels Bôer 1968, Pinheiro \& Balick 1987).

6. Geonoma rubescens $\mathrm{H}$. Wendl. ex Drude, Fl. bras. 3(2): 491.1882.

Figura 1: e

Plantas ca. 1,16 m alt., cespitosas. Estipe geralmente ausente, quando presente com até 
$15 \mathrm{~cm}$ alt. e ca. $8 \mathrm{~cm}$ diâm., ereto; castanho, cicatrizes foliares sulcadas evidentes, ca. $1 \mathrm{~cm}$ larg., dispostas regularmente, inerme. Folhas ca. 8; 70-106 cm compr., marcescentes não observadas; bainha 7-10 x 2,7-3 cm, fibrosa, parda, inerme; pecíolo 42-56 cm compr., triangular canaliculado, inerme; raque 22,5-26,5 cm compr., inerme; folíolos 3-5, verdes em ambas faces, irregularmente distribuídos e dispostos em um único plano, medianos 27-35 x 3,2-4,1 cm, ápice acuminado, margem lisa. Inflorescência arqueada, interfoliar; profilo não observado; bráctea peduncular 16-20 x 1,6-2,3 $\mathrm{cm}$, fibrosa, recoberta por indumento ferrugíneo; raque 21-24 cm compr., ca. $1,1 \mathrm{~cm}$ diâm., densamente recoberto por indumento ferrugíneo; raquilas 2-3, 19-24 cm compr., densamente recobertas por indumento ferrugíneo, sem ramificações de segunda ordem. Flores estaminadas ca. 4 × $3 \mathrm{~mm}$, creme; sépalas ca. $3 \times 1 \mathrm{~mm}$, acuminadas; pétalas ca. $4 \times 2 \mathrm{~mm}$, elípticas; estames 6 , monadelfos, filetes ca. $3 \mathrm{~mm}$ compr., anteras ca. $1 \mathrm{~mm}$ compr., dorsifixas. Flores pistiladas ca. $5 \times 4 \mathrm{~mm}$, creme; sépalas ca. $3 \times 2 \mathrm{~mm}$, carenadas; pétalas ca. 4 × $2 \mathrm{~mm}$, elípticas; pistilo ca. $4 \mathrm{~mm}$ compr. Frutos ca. 1,6 cm compr., ca. 1,5 cm diâm., perianto persistente; epicarpo ca. $1 \mathrm{~mm}$ de espessura, lenhoso, nigrescente, glabro; mesocarpo ca. $1 \mathrm{~mm}$ de espessura; endocarpo ca. $1 \mathrm{~mm}$ de espessura, fibroso, pardo. Semente 1; endosperma carnoso, homogêneo, alvo.

Nome popular local: sem relatos.

Material examinado: BRASIL. MINAS GERAIS: Descoberto. Reserva Biológica da Represa do Grama: II.2000, Faria et al. 71, fl. (CESJ); XII.2001, Castro et al. 737, fl. (CESJ, RB, SPF); IX.2002, Forzza et. al 2242, fl. e fr. (BHCB, CESJ, MBM, SPF); X.2002, Lopes et al. 46, fl. (CESJ, CTES).

Geonoma rubescens pode ser diferenciada de G. brevispatha e das demais espécies de Palmae da Reserva pelo hábito cespitoso, presença de poucos e largos folíolos (Figura 1 e), além de inflorescência interfoliar, com raquilas não ramificadas em segunda ordem sendo toda densamente coberta por indumento ferrugíneo.

Tal espécie apresenta-se distribuída pela costa atlântica do Brasil nos estados de Pernambuco a Santa Catarina. Ocorre no interior de florestas úmidas em solos encharcados ou bem drenados variando de argilosos a areníticos (Henderson et al. 1995).

\section{Syagrus romanzoffiana (Cham.)}

Glassman, Fieldiana, Bot. 31(17): 382. 1968.

Plantas ca. $16 \mathrm{~m}$ alt., solitárias. Estipe ca. $5 \mathrm{~m}$ compr. e até $1 \mathrm{~m}$ diâm., ereto, cinéreo- alvo, cicatrizes foliares dispostas irregularmente, inerme. Folhas 14-18; ca. 5,7 m compr., algumas marcescentes; bainha 1,5-2 × 0,6 m, fibrosa, pardacenta, inerme; pecíolo ca. $98 \times 6 \mathrm{~cm}$, subcilíndrico canaliculado, inerme; raque 2,8-3,3 m compr., inerme; folíolos ca. 204, discolores, distribuídos irregularmente e dispostos em diferentes planos, com nervura mediana amarela; folíolos medianos 114-118 x 4,1-4,8 cm, ápice acuminado a assimétrico, margem lisa. Inflorescência pendente, interfoliar; profilo não observado; bráctea peduncular 130-140 × $30 \mathrm{~cm}$, lenhosa, amarela, inerme; raque 1,4-1,5 m, ca. 12 cm diâm., inerme; raquilas numerosas, ca. 32 $\mathrm{cm}$ compr., inermes. Flores estaminadas 9-14 x 5-8 mm, creme; sépalas 1-2 $\times 1 \mathrm{~mm}$, acuminadas; pétalas 8-12 x 3-5 mm, acuminadas; estames6, dialistêmones; filetes 1-3 mm compr.; anteras 5-7 mm compr., dorsifixas. Flores pistiladas creme, 7-11 x $6 \mathrm{~mm}$; sépalas ca. $6 \mathrm{x}$ $4 \mathrm{~mm}$, ápice agudo; pétalas ca. 7 x $5 \mathrm{~mm}$, ápice agudo; pistilo ca. $7 \mathrm{~mm}$ compr. Frutos 1,9-2,2 cm compr., ca. 2 cm diâm, perianto decíduo; epicarpo 1-2 $\mathrm{mm}$ de espessura, fibroso, alaranjado, coberto por mucilagem; mesocarpo ca. $1 \mathrm{~mm}$ de espessura, fibroso a carnoso, pardo, mucilaginoso; endocarpo ca. $1 \mathrm{~mm}$ de espessura, lenhoso, castanho. Semente 1; endosperma carnoso, homogêneo, alvo.

Nome popular local: coquinho-babão Material examinado: BRASIL. MINAS GERAIS: Descoberto: Reserva Biológica da Represa do Grama: IX.2001, Fazza et al. 7, fl. e fr. (CESJ). 
O gênero Syagrus apresenta 30 espécies distribuídas na América do Sul, com maior diversidade na região central do Brasil. Para os domínios de floresta atlântica são registradas 14 espécies. (Henderson et al. 1995).

Syagrus romanzoffiana distribui-se pela costa brasileira, avançando para o interior do continente até os estados de Goiás, Mato Grosso e Mato Grosso do Sul, além de Paraguai, Argentina e Uruguai. Apresenta grande amplitude ecológica ocorrendo em diferentes ecossistemas (Henderson et al. 1995). Na Reserva foram encontrados poucos indivíduos em áreas extremamente alteradas.

Esta espécie é utilizada em muitos países como planta ornamental, devido ao aspecto majestoso, que lhe conferiu o chamativo de "palmeira-rainha" (Marcato \& Pirani 1999). $\mathrm{Na}$ Região da Reserva a população local utiliza os frutos na alimentação.

\section{Agradecimentos}

Os autores agradecem a FAPEMIG e a Universidade Federal de Juiz de Fora pelas bolsas concedidas. A Patrícia Carneiro Lobo Faria, coordenadora do Projeto e ao Sr. Luiz, mateiro da Reserva, por toda ajuda no trabalho de campo e na coletas das palmeiras. Ao João Marcelo de Alvarenga Braga, Ricardo Carneiro da Cunha Reis e dois assessores anônimos pela leitura e sugestões.

\section{REFERÊNCIAS BIBLIOGRÁFICAS}

CETEC. 1987. Diagnóstico Ambiental de Minas Gerais.

Anderson, A. B. \& Balick, M. J. 1988. Taxonomic of the Babassu complex (Orbgnya spp. - Palmae). Systematic Botany 13(1): 32-50.

Glassman, S. 1977. Preliminary taxonomic studies in the palms genus Attalea H. B. K. Fieldiana Botany 38(5): 31-61.

Henderson, A., Galeano, G. \& Bernal R. 1995. Field Guide to the Palms of Americas. Pricetom University Press. 352 p.
Martins, C. S. 2000. Caracterização física e fitogeográfica de Minas Gerais. In M. P. Mendonça \& L. V Lins (orgs.). Lista Vermelha das Espécies Ameaçadas de Extinção da Flora de Minas Gerais. Fundação Biodiversistas. Belo Horizonte. $157 \mathrm{p}$.

Marcato, A. C. \& Pirani, J. R. 1999. A família Palmae na Cadeia do Espinhaço em Minas Gerais. Dissertação de Mestrado. Instituto de Biociências. Universidade de São Paulo. São Paulo. 87 p.

Meira-Neto, J. A. A.; Souza, A. L.; Silva, A. F. \& Paula, A. 1997. Estrutura de uma floresta estacional semidecidual submontana em área diretamente afetada pela Usina Hidrelétrica de Pilar, Ponte Nova, Zona da Mata de Minas Gerais. Revista Árvore 21(3): 337-344.

Mello-Filho, L. E.; Sommer, G. V. \& Peixoto, A. L. 1992. Centuria plantarum brasiliensis extintionis minitata. Sociedade Botânica do Brasil. IBAMA. 167p.

Mendonça, M. P. \& Lins, L. V. 2000. Lista Vermelha das Espécies Ameaçadas de Extinção da Flora de Minas Gerais. Fundação Biodiversistas. Belo Horizonte. $157 \mathrm{p}$.

Menini Neto, L.; Almeida, V. R. \& Forzza, R. C. 2004. A família Orchidaceae na Reserva Biológica da Represa do Grama - Descoberto, Minas Gerais, Brasil. Rodriguésia 55 (84): 137-156.

Moore, H. E. Jr. \& Uhl, N. W. 1982. Major Trends of Evolution in Palms. Botanical Review 48: 1-70.

Noblick, L. R. 1991. The indiginous palms of the state of Bahia, Brasil. Ph. D. diss., University of Illinois, Chicago.

Oliveira-Filho, A. T. de; Scolforo, J. R. S. \& Mello, J. M. 1994. Composição florística e estrutura comunitária de um remanescente de floresta semidecídua montana em Lavras, MG. Revista Brasileira de Botânica 17(2): 167-182.

Pinheiro, C. U. B. \& Balick, M. J. 1987. Brazilian Palms. Notes on their uses and 
vernacular names, compiled and translated from Pio Corrêa's "Dicionário das plantas úteis do Brasil e das Exóticas Cultivadas", with updated nomenclature and added ilustrations. Contributions of New York Botanical Garden. 17: 1-50.

Radford, A. E., Dickison, W. C, Massey, J. R. \& Bell, C. R. 1974. Vascular Plant Systematics. New York, Harper \& Row Publ.

Silva, A. F. 2000. Floresta Atlântica. In M. P. Mendonça \& L.V. Lins (org.). Lista vermelha das espécies ameaçadas de extinção da flora de Minas Gerais. Fundação Biodiversitas, Belo Horizonte, $157 \mathrm{p}$.

Uh1, N. W. \& Dransfield, J. 1987. A Classification of Palms Based on the Work of Harold E. Moore Jr. Genera Palmarum. Allen Press. 33 p.

Wessels Bôer, J. 1968. The geonomoid palms. Verh. Kon. Ned. Akad. Wetensch, Afd. Natuurk., Tweede Sect. ser. 2, 58: 1-202. 